\title{
KONTRIBUSI KELINCAHAN TERHADAP KEMAMPUAN DRIBBLING BOLABASKET ATLET SMA NEGERI 1 LEBONG UTARA
}

\author{
Feby Elra Perdima \\ Universitas Dehasen Bengkulu \\ Email: Perdima.elra@gmail.com
}

\begin{abstract}
ABSTRAK
Berdasarkan pengamatan peneliti terhadap pelaksanaan Kegiatan di klub bolabasket SMA Negeri 1, bahwa kemampuan Dribbling para pemain bolabasket kurang baik sehingga menyebabkan minimnya prestasi yang didapat. Masalah inilah diduga disebabkan oleh beberapa faktor, antara lain rendahnya tingkat kelincahan dari pemain. Penelitian ini bertujuan untuk mengetahui Kontribusi kelincahan terhadap Kemampuan Dribbling Bolabasket Atlet SMA Negeri 1. Metode penelitian ini adalah metode korelasional. Populasi penelitian ini seluruh pemain klub bolabasket SMA Negeri 1 sebanyak 23 orang putera dan 3 orang puteri, sedangkan sampel diambil secara purposive sampling, dimana teknik purposive sampling adalah teknik pengambilan sampel dengan didasarkan ketentuan tertentu, untuk itulah maka dalam penelitian ini penulis hanya mengambil sampel atlet bolabasket putera saja. Ini didasarkan dengan pertimbangan adanya perbedaan kemampuan fisik antara atlet putera dengan atlet puteri. Sehingga diperoleh sampel dengan jumlah 23 orang pemain putera. Tempat pelaksanaan penelitian di lapangan basket SMA Negeri 1 Lebong Utara, adapun waktu penelitian adalah bulan juli 2011. Data kelincahan diambil dengan tes Zigzag Run, dan data Kemampuan Dribbling diambil dengan tes Dribbling. Teknik analisis data penelitian ini menggunakan teknik dengan analisis korelasi sederhana dan korelasi ganda.

Hasil analisis data menunjukkan bahwa: Terdapat kontribusi yang signifikan antara kelincahan dengan kemampuan Dribbling Bolabasket atlet SMA Negeri 1 , dengan nilai $r=0,480$ didapat r2 $=0,230$, adapun besar kontribusinya adalah $23 \%$.
\end{abstract}

Kata Kunci : Keincahan, Kemampuan Dribbling

\begin{abstract}
Based on the observations of study on the implementation of activities at the basketball club SMA Negeri 1, that of Dribbling ability basketball athlete are less good, thus causing the lack of achievement obtained. This problem is thought to be caused by several factors, including the low level of agility of players. This study aims to determine the agility contribution to the Dribbling ability Basketball of Athletes SMA Negeri 1North Lebong. This research method is correlation method. The population of this study all players basketball club SMA Negeri 1 as many as 23 male and 3 female, while the sample taken by purposive sampling, where it is a sampling technique based on certain provisions, that is why in this study the whiter only take samples from Basketball athlete male. This is based on the consideration of the difference in physical ability between athlete male and female athlete. So that the sample obtained with total of 23 men athlete. The place of study is in the field of basketball of SMA Negeri 1 North Lebong, while the time of the study is July 2011. Data agility is taken with Zigzag Run test, and data Dribbling capability is taken by Dribbling test. Data analysis technique of this study use technique with simple correlation analysis and correlation double. The results of data analysis showed that: There is a significant contribution between agility with the Dribbling ability of Basketball athletes SMA Negeri 1, with the value $r=0.480$ obtained $r 2=0.230$, then the contribution is $23 \%$.
\end{abstract}

Keywords: Agility, Dribbling Ability

Journal Sport Area Penjaskesrek FKIP Universitas Islam Riau 


\section{PENDAHULUAN}

Bolabasket adalah suatu permainan yang dimainkan secara tim yang setiap tim terdiri dari 5 orang, sehingga diperlukan suatu kerjasama tim dan keterampilan dari masing-masing individu. Dalam permainan bolabasket, seorang pemain dituntut selalu bergerak sambil memperagakan teknik-teknik dasar bolabasket, berusaha memasukkan bola ke ring lawan sebanyak-banyaknya tanpa mendapat gangguan dari lawan serta berusaha mencegah lawan untuk memasukkan bola ke dalam ring. Hal ini artinya, untuk dapat bermain bolabasket dengan baik dibutuhkan penguasaan teknik yang baik dan kualitas fisik yang memadai. seorang pemain bolabasket juga harus menguasai berbagai teknik dasar dalam bermain bolabasket seperti menembak, menggiring, mengumpan, pivot dan lain-lain. Bagi seorang atlet bahwa olahraga merupakan ajang untuk berkompetisi untuk meraih suatu prestasi yang setinggi-tinggi nya. Untuk meraih prestasi tersebut di perlukan usaha melalui perencanaan dan pelaksanaan yang terarah, terkoodinir dengan penyedian saran prasarana yang memadai. Dalam undang - undang sistem keolahragaan di jelaskan." Olahraga prestasi adalah olahraga yang membina dan mengembangkan olahraga secara terencana, berjenjang dan berkelanjutan melalui kompetisi untuk mencapai prestasi dengan dukungan ilmu pengetahuan dan teknologi keolahragan (UU.RI No 3.2005:3).

Dari sekian banyak cabang olahraga prestasi, yang dibina bolabasket merupakan cabang olahraga yang banyak di gemari oleh masyarakat. Di mana orang bukan hanya memainkannya melainkan juga tertarik untuk menontonnya. Oleh sebab itu cabang olahraga bolabasket banyak di gemari oleh masyarakat umum, kalangan anak-anak, maupun dewasa dan remaja. Ide atau tujuan dari permainan bolabasket adalah "memasukan bola ke ring dan mempertahankan ring tersebut agar tidak kemasukan bola".

SMA Negeri 1 adalah salah satu sekolah yang berada di Kabupaten Lebong, di mana sekolah ini memiliki beberapa klub, salah satunya yaitu klub bolabasket SMA Negeri 1 Lebong Utara yang diberi nama klub SMA Lebra yang sudah melaksanakan proses latihan yang kontinu dan terencana, serta memiliki program latihan yang terencana. Di samping itu SMA Negeri 1 memliki tenaga pelatih yang terampil atau yang profesional serta pelatih yang memiliki lisensi C. Ideal nya SMA Negeri 1 ini melahirkan para pemain-pemain basket yang profesional serta memiliki kemampuan dribbling yang bagus tapi kenyataan setelah melakukan pengamatan penulis pada SMA Negeri 1 saat melakukan latihan atau pun pertandingan, kemampuan dribbling yang mereka miliki masih kurang baik. Hal ini terlihat saat melakukan dribbling bola yang mereka kuasai sangat mudah dirampas oleh lawan karena kemampuan merubah arah tubuh mereka saat berbalik arah dalam menguasai bola tersebut kurang baik sehingga melakukan dribbling kurang lancar.

Kurangnya kemampuan dribbling pemain SMA Negeri 1 membuat para pemain sulit mengatur tempo pemainan maupun menguasai permainan. Sehingga sulit untuk mencari kesempatan dalam memasukan bola ke dalam ring sehingga tujuan dari permainan bolabasket tidak tercapai dan kemenangan sulit didapat. Oleh sebab itu lah penulis tertarik untuk melakukan penelitian tentang kontribusi kelincahan terhadap kemampuan dribbling.

Permainan bolabasket diciptakan oleh Dr. James A. Naismith seorang bangsa Amerika yang berkerja sebagai Guru Pendidikan Jasmani pada sekolah perkumpulan orang Kristen di Springfield Massachuscts Amerika Serikat pada tahun 1891. Nama bolabasket ini pada dasarnya berasal dari bola yang dimasukan ke dalam sasaran berupa 
keranjang "peach" yang diselubungi di bawahnya. Bolabasket merupakan permainan bola besar yang dimainkan oleh dua regu yang terdiri dari 5 orang pemain dalam setiap regu berusaha memasukan bola ke dalam ring lawan dengan sebanyak-banyaknya agar memperoleh suatu kemenangan.

Kosasih (2008:2) mengemukakan bahwa "bolabasket permainan yang menggunakan kecepatan (kaki dan tangan) dan kesigapan (keseluruhan gerak tubuh) dalam waktu yang tepat". Dalam melatih kita harus terus-menerus menekankan prinsip melakukan semua gerakan yang benar, dengan cepat dan disaat yang tepat. Semua ini harus dilakukan saat mengembangkan serta melatih skill individu pemain, fisik, emosi dan ke kompakan tim, baik dalam posisi defence maupun offense. Arifin (2004:16) menjelaskan bahwa "bolabasket merupakan olahraga yang mengandung unsur-unsur gerakan yang komplek dan beragam, artinya gerakan-gerakan yang dibutuhkan dalam bermain bolabasket merupakan gabungan dari unsur-unsur gerakan yang saling menunjang". Berdasarkan kutipan di atas dapat dikatakan bahwa bolabasket merupakan cabang olahraga yang memiliki unsur-unsur gerakan yang sangat banyak sekali oleh karena itu seorang pemain bolabasket harus memahami seluruh gerakan yang ada di dalam permainan bolabasket.

Soedikun (1992:57) mengemukakan bahwa "dribbling adalah salah satu cara yang di perbolehkan oleh peraturan untuk membawa lari bola ke segala arah. Seseorang pemain boleh membawa bola lebih dari satu langkah asalkan bola sambil dipantulkan". Dribbling merupakan bagian yang tak terpisahkan dari permainan bolabasket dan penting bagi atlet untuk bermain individual maupun tim. Adnan (1999:32) mengemukakan bahwa "dribbling merupakan bentuk gerakan membawa bola yang disyahkan oleh peraturan". Keterampilan ini juga merupakan kemahiran dasar yang harus dikuasai oleh pemain bolabasket. Untuk membawa maju bola pemain harus memantulkan bola terlebih dahulu ke lantai dengan salah satu tanganya atau berselangseling dengan kedua tangan. Dribbling adalah salah satu cara untuk membawa bola ke segala arah dengan lebih dari satu langkah asal bola sambil dipantulkan dan merupakan usaha untuk mengamankan bola dari rampasan lawan".

Menurut Elra (2017:50) mengemukakan bahwa "dribbling adalah salah satu teknik dasar dalam bolabasket dengan cara menguasai bola sambil bergerak untuk mengamankan bola dari rampasan oleh lawan. Bola dipantulkan ke lantai, sesuai peraturan yang disahkan. Pada awalnya bola harus lepas dari tangan sebelum kaki anda diangkat ke lantai, sementara mengiring bola tidak boleh menyentuh bola dengan dua tangan. Sedangkan Khoeron (2017:41) mengemukakan bahwa dribbling adalah sebuah pergerakan menggiring bola untuk menghindari lawan sampai mencetak poin. Teknik ini dilakukan dengan memantul-mantulkan bola ke lantai dengan ritme tertentu.

Berdasarkan pendapat para ahli di atas penulis menyimpulkan bahwa dribbling adalah suatu cara membawa bola agar tetap menguasai bola sambil bergerak untuk mengamankan bola dari rampasan oleh lawan. Di mana bola dipantulkan ke lantai, sesuai peraturan yang disahkan. Pada awalnya bola harus lepas dari tangan sebelum kaki anda diangkat ke lantai, sementara mendrible tidak boleh menyetuh bola dengan dua tangan.

Menurut Kusyanto (1994:32) jenis mengiring bola terbagi atas 2 jenis di antara lain yaitu :1) Mengiring bola tinggi bertujuan untuk kecepatan), 2) Mengiring bola rendah (untuk kontrol atau penguasaan. Terutama dengan pemain lawan dalam menerobos pertahanan lawan). Ada beberapa manfaat khusus dribbling menurut Wissel (1996:95) antara lain : 
a. Memindahkan bola keluar dari daerah padat penjagaan ketika operan tidak memungkinkan lagi

b. Memindahkan bola ketika penerimaan tidak bebas penjagaan

c. Memindahkan bola pada saat fast break karena rekan tim tidak bebas penjagaan untuk mencetak angka

d. Menembus penjagaan kea rah ring

e. Menarik perhatian penjaga untuk membebaskan rekan tim

f. Menyiapkan permainan menyerang

g. Memperbaiki posisi sebelum mengoper bola ke rekan\

h. Membuat peluang untuk menembak.

Dalam Kamus Bahasa Indonesia, Poerwadarminta (1986:22) menyatakan bahwa kelincahan berasal dari suku kata lincah yang berarti gesit atau cekatan". Kelincahan merupakan salah satu komponen kesegaran jasmani yang harus selalu ditingkatkan dan dikembangkan. Pate dalam Suhendro (2002:4) menyatakan kelincahan adalah "Kemampuan seseorang untuk merubah arah dalam keadaan bergerak". Orang yang lincah adalah orang yang mampu merubah satu posisi ke posisi yang berbeda, dengan kecepatan tinggi dan koordinasi gerak yang baik. Pendapat lain dikemukakan oleh Wilmore dalam Muhajir (2004:3) menyatakan kelincahan adalah "Kemampuan seseorang untuk dapat merubah arah dengan cepat dan tepat pada waktu bergerak tanpa kehilangan keseimbangan". Ismaryati (2006: 41) kelincahan adalah kemampuan untuk merubah arah dan posisi tubuh atau bagian-bagiannya secara cepat

Berdasarkan pendapat para ahli di atas maka ditarik kesimpukan tentang pengertian kelincahan. Kelincahan adalah kemampuan untuk merubah arah dan posisi tubuh dengan cepat dan tepat pada waktu sedang bergerak tanpa kehilangan keseimbangan dan kesadaran akan posisi tubuh. Menurut Darwis dan Basa yang dikutip oleh Avick Vidyo (2010:21) bahwa fungsi kelincahan dan macam kelincahan adalah sebagai berikut :

1. Mengkoordinasi gerak-gerak berganda (simultan).

2. Mempermudah penguasaan teknik-teknik yang tinggi dalam setiap cabang olahraga.

3. Gerakan efektif, efisien dan ekonomois.

4. Mempermudah orientasi terhadap lawan dan lingkungan.

\section{METODE PENELITIAN}

Jenis penelitian ini adalah penelitian korelasi yang ingin melihat hubungan antara variabel bebas dan terikat. Sudjana (1992:63) mengemukakan bahwa: Penelitian korelasi merupakan penelitian untuk mengetahui ada tidaknya hubungan antara dua variabel, besar tidaknya hubungan dua variabel tersebut dinyatakan dalam bentuk koefisien kerelasi". Adapun variabel bebas adalah kelincahan. Variabel terikat adalah kemampuan dribbling bolabasket. Populasi dalam penelitian ini adalah seluruh atlet bolabasket SMA Negeri 1 Lebong Utara berjumlah 26 orang yaitu putra berjumlah 23 orang dan puteri berjumlah 3 orang. Serta sampel dengan jumlah 23 orang pemain putera mengunakan teknik purposive sampling didasarkan dengan pertimbangan adanya perbedaan kemampuan fisik antara atlet putera dengan atlet puteri. Tempat pelaksanaan penelitian di lapangan basket SMA Negeri 1 Lebong Utara, adapun waktu penelitian adalah bulan juli 2011. Data kecepatan diambil dengan tes lari sprint 30 meter, dan data kemampuan dribbling diambil dengan tes dribbling. Teknik analisis data penelitian ini menggunakan teknik dengan analisis korelasi sederhana dan korelasi ganda. 


\section{HASIL DAN PEMBAHASAN}

Setelah uji persyaratan analisis dilakukan, dan ternyata semua skor tiap variabel penelitian memenuhi persyaratan untuk dilakukan pengujian statistik lebih lanjut, maka selanjutnya dilaksanakan pengujian hipotesis. Dalam penelitian ini ada tiga hipotesis penelitian, yaitu: (1) Terdapat kontribusi yang signifikan antara kecepatan dengan kemampuan dribbling Bolabasket atlet SMA Negeri 1 Lebong Utara, (2) Terdapat kontribusi yang signifikan kecepatan secara bersama-sama dengan kemampuan dribbling bolabasket atlet SMA Negeri 1 Lebong Utara. Berikut ini disajikan hasil pengujian terhadap ketiga hipotesis penelitian yang telah diajukan di atas.

\section{Seberapa Besar Kontribusi Antara Kelincahan Dengan Kemampuan Dribbling Bola}

Analisis korelasi terhadap kelincahan dengan keterampilan dribbling bola menghasilkan koefisien korelasi sebesar $r_{y 1}=0,480$, dan koefisisen determinasi $r^{2}=$ 0,230 . Untuk lebih jelasnya dapat dilihat rangkuman hasil analisis tabel berikut ini.

Tabel 1. Rangkuman Hasil Analisis Korelasi Antara Variabel Kelincahan (X1) dan Keterampilan Dribbling (Y)

\begin{tabular}{ccccc}
\hline $\begin{array}{c}\text { Korelasi } \\
\text { Antara }\end{array}$ & $\begin{array}{c}\text { Koefisien Korelasi } \\
(\mathrm{r})\end{array}$ & $\begin{array}{c}\text { Koefisien } \\
\text { Determinasi }\left(\mathrm{r}^{2}\right)\end{array}$ & $\mathrm{t}_{\text {hitung }}$ & $\begin{array}{c}\mathrm{t}_{\text {tabel }} \\
\alpha=0,05\end{array}$ \\
\hline X1 dan Y & 0,480 & 0,230 & 2,507 & 2,080 \\
\hline
\end{tabular}

Keterangan: Koefisien korelasi signifikan $\left(\mathrm{t}_{\text {hit }}=2,507>\mathrm{t}_{\mathrm{tab}}=2,080\right)$.

Berdasarkan uji keberartian korelasi antara pasangan skor kelincahan $\left(\mathrm{X}_{1}\right)$ dengan keterampilan dribbling bola (Y) sebagaimana terlihat pada tabel di atas diperoleh $t_{\text {hitung }}$ $=2,507>\mathrm{t}_{\text {tabel }}=2,080$ pada taraf signifikansi $\alpha=0,05$. Dengan demikian, $\mathrm{H}_{\mathrm{a}}$ yang mengatakan terdapat hubungan yang signifikan antara kelincahan terhadap keterampilan dribbling bolabasket atlet SMA Negeri 1 Lebong Utara diterima, konsekuensinya $\mathrm{H}_{0}$ ditolak. Kemudian terdapat sumbangan sebesar 23\%. Temuan ini menyimpulkan bahwa terdapat hubungan kelincahan yang terhadap keterampilan dribbling bolabasket atlet SMA Negeri 1 Lebong Utara. Hal ini berarti semakin baik kelincahan seseorang, maka semakin baik pula keterampilan dribbling bolabasket.

Selanjutnya untuk menentukan besarnya kontribusi kelincahan terhadap keterampilan dribbling bola ditunjukkan dari hasil analisis koefisien determinasinya yaitu sebesar 0,230. Hal ini berarti variabel kelincahan memberi kontribusi sebesar 23 $\%$ terhadap keterampilan dribbling bolabasket.

\section{KESIMPULAN}

Berdasarkan analisis data dan pembahasan yang telah dipaparkan terdahulu, maka dapat dikemukakan kesimpulan sebagai berikut: Terdapat kontribusi yang signifikan antara kelincahan dengan kemampuan dribbling bolabasket atlet SMA Negeri 1 Lebong Utara, ini ditandai dengan hasil penelitian yang diperoleh yaitu nilai $r=0,480$ didapat $r^{2}$ $=0,230$, adapun besar kontribusinya adalah $23 \%$. 


\section{DAFTAR PUSTAKA}

Arifin, Mochamad. 2004. Metode Pelatihan Bolabasket dasar. Surabaya. Diktat.

Avick Vidyo Hantoro. 2010. Sumbangan Kelincahan, Kelentukan Dan Kemampuan Sit Up 60 Detik Terhadap Kemampuan Menggiring Bola Siswa Putra SMP Muhamadiyah I Dlingo Bantul Yogyakarta. Skripsi. Yogyakarta: FIK UNY Yogyakarta.

Elra.Perdima.2017. Bolabasket Dasar. Bengkulu: Universitas Dehasen Bengkulu Press.

Khoeron, Nidhom.2017. Basket Pintar. Jakarta Timur: Anugrah.

Fardi, Adnan. 1999. Bolabasket Dasar. Fakultas Ilmu Keolahragaan : UNP.

Ismaryanti. 2008. Tes dan Pengukuran Olahraga. Surakarta: Sebelas Maret Universitas Press.

Kosasih, Danny. 2008. Fundamental Basketball. Semarang : Karangfuri.

Kusyanto, Yanto.1994. Pendidikan Jasmani dan Kesehatan. Bandung : Ganesa.

Muhajir. 2004. Pendidikan Jasmani Teori Dan praktek. Jakarta : Erlangga.

Poewadarmenata.1986. Kamus Besar Bahasa Indonesia.Jakarta: Balai Pustaka.

Sodikun,Imam.1992. Olahraga Pilihan Bolabasket. Padang: Departemen Pendidikan dan Kebudayaan Direktorat Jendral Pendidikan Tinggi.

Sudjana.1992. Metode Statistik.Bandung: Tarsito.

Suhendro.2002. Dasar-Dasar Kepelatihan. Jakarta : Universitas Terbuka.

Tim Pengajar Bolabasket.2003. Buku Ajar Bolabasket Dasar. Padang : FIK UNP.

Undang-Undang RI No. 3.2005. Sistem Keolahragaan Nasional.Jakarta : Pustaka Yustisia. 